\title{
The Quality of Service of Vehicle Plate Online Registration in Cambodia: Assessment and Perspective of Online Customers
}

\author{
Lor Mouy Ngich ${ }^{*}$ ) \\ ${ }^{1}$ Master of Public Management, Government Officer Department of Personnel and Training, \\ Anti-Corruption Unit, Cambodia. Building 54, Phsar Thmey 3, Daun Penh, Phnom Penh, \\ Cambodia.
}

Received: 2021-04-24; Accepted: 2021-05-05; Published: 2021-10-31

\begin{abstract}
Limited evidence is presented for the evaluation of a particular online service, especially in developing countries. Cambodia introduced an online vehicle plate registration in 2017. Since then, there have not been any research studies on the quality of this public online service after the implementation. This research has two main aims: (1) to describe the quality of online vehicle plate registration and (2) to present citizens' perspectives who have experienced this online service provided by the Ministry of Public Works and Transport (MoPWT). The research employs a mix-method combining online questionnaires (100) and in-depth interviews (10) to answer the research questions regarding website design, reliability, citizen support, trust, and accessibility. The average score for all components and overall service quality is 2 , suggesting that people perceive the service as having low quality. The results strengthen the influence of reliability and citizen support on the people's perception of service quality as claimed by researchers. However, it contradicts the previous research in that website design though not well appreciated does not have much influence on the quality of service as claimed. The research also indicates some issues with the online system. Building more trust, providing better citizen support in time, and finally reducing the chances of corruption are components of services quality that should be improved to increase the number of people using the online service and increase citizen satisfaction.
\end{abstract}

Keywords: Online Service; Service Quality; Customers; Cambodia; Perspective; Citizen Support; Reliability

How to Cite: Ngich, L.M. (2021). The Quality of Service of Vehicle Plate Online Registration in Cambodia: Assessment and Perspective of Online Customers. Journal of Contemporary Governance and Public Policy, 2(2), 106-121. https://doi.org/10.46507/jcgpp.v2i2.37.

Permalink/DOI: https://doi.org/10.46507/jcgpp.v2i2.37 


\section{Introduction}

The Royal Government of Cambodia has introduced its application of ICTs in the early 21st century by establishing two legal entities. They are the National ICT Development Authority (NiDA) and Government Administrative Information System (GAIS). These entities were created to generate more revenue and offer quick and easy access services to citizens. GAIS has four flagship plans: systems to approve electronically, to register real estate or property, to register residents, and to register vehicles (NiDA \& JICA, 2009). E-services could be referred to as services offered or delivered electronically through online tools (IGI, 2020).

E-government is regarded as a useful tool in strengthening the administration tasks and its complicated process to deliver public services, distribute and receive the necessary information, facilitate the transaction by integrating a variety of individuals or simple systems and services, with the participation of government itself, and clients including citizens and business people (Bertot, Jaeger, \& Grimes, 2012; Mistry \& Jalal, 2012). It is highly expected to improve government and the governmental process (Milakovich, 2012). Significantly, scholars have argued that e-government could be a useful tool in fighting against corruption (Abu-Shanab, 2015; Wirtz \& Birkmeyer, 2015).

Scholars and politicians have emphasized the benefits of applying e-government. Nevertheless, in practice, work to measure the quality of online services when it is placed in use in developing countries is limited in spite of a few are mentioned in the following paragraphs. It is of critical importance to examine the practice of online service, whether citizens are satisfied with the quality and if there are any issues affecting the quality of service. Therefore, this research means to capture customers' perspectives toward service quality and some reasons for such perspectives.

Al-nasser et al. (2013) use a quantitative method to determine the impacts of e-service quality on perceived trust. In the same vein, Noorshella et al. (2015) employ online surveys to determine the influence of e-commerce website quality on customer satisfaction. Chu et al. (2012) distribute questionnaires to study the relationship between the quality of ebank service and client satisfaction and their trust. Vatolkina et al. (2020) also deploy questionnaires to analyze and determine the relationship between customer experience and their satisfaction with e-service.

E-service quality models are formed depending on the common acknowledgment about the relationship between the service quality and outcome variables, including customer satisfaction, their intention to reuse or repurchase the products, and to spread of product information from one to another (Blut, Chowdhry, Mittal, \& Brock, 2015). Taherdoost and Taherdoost (2018) developed an Adoption Model to evaluate customers' reception of eservice, which he called the E-service Technology Acceptance Model. This model puts the spotlight on the overlooked elements which have significant influences on service quality, including security and satisfaction of end-users.

Papadomichelaki and Mentzas (2012) constructed the e-government service quality model, which was recognized as e-GovQual. The six quality dimensions identified are "Ease of Use, Trust, Functionality of the Interaction Environment, 
Reliability, Content, and Appearance of Information, and Citizen Support" (p. 172). There are 33 e-government attributes. In assessing the theoretical model, they conducted an empirical study with 630 online participants. Consequently, they found the four quality dimensions "Reliability, Efficiency, Citizen Support, and Trust" (p. 172), by employing 25 quality attributes after evaluating the list of all 33 e-government quality attributes. The researchers built a conceptual framework to assess egovernment services by depending on the term quality's underlying dimensions. E-GovQual has four dimensions and 21 item scales. The four dimensions are "reliability, efficiency, citizen support, and trust." Consequently, this research claims to validate the content, conduct a systemic sample, and tested the universal content. The 21 scales were identified and tested before the distribution of surveys.

Alanezi et al. (2010, p10) suggested a scale that involved seven dimensions and 26 items in measuring the quality of e-service in an e-government field. Those dimensions are "website design, reliability, responsiveness, security/privacy, personalization, information and ease of use". Nevertheless, they merely constructed the model conceptually without empirical testing. The dimensions consist of SERVQUAL and the other two aspects, information and ease of use. However, these were not justified in a way that they could be applied to an e-government context.

Tan et al. (2013) conducted an empirical study by following the SERVQUAL model (Assurance, Empathy, Reliability, Responsiveness, Tangibility). The authors aim to determine the influences of the frequent transactions for the services on citizens' quality perceptions about e-government websites. With the participation of 647 e-government service users, they found that citizens placed a significant focus on content functionalities' effectiveness with an increase in transaction frequency. That can be implied that the increase in transaction frequency can positively influence service quality and service quality in general.

Sang et al. (2009) conduct their research on the e-government in Cambodia by adopting the Technology Acceptance Model (TAM). Consequently, they concluded that three determinants, such as "perceived usefulness, trust, and relative advantage," were critical. This is because they can predict the level of utilization of those public services electronically. People would use more of those e-services when they have confidence in the services they received and when they complete their transactions.

Having reviewed the previous research, the researcher identifies gaps of study. First, the quality of eservice has not been well-examined in developing countries. What people have experienced and their opinions towards the quality of the online service system is not well-described. Second, this study adjusts the eGovQual, ETAM, and SERVQUAL scale items to establish dimensions of eservice quality. This ensures that both e-service quality and citizen satisfaction are included in conducting an assessment of overall service quality. Third, most of the research uses a quantitative method to assess the quality of e-service. By collecting the recent primary data in 2020 with a mixed method to measure the quality of online service and understand what people perceive of the service, there will be benefits to the public and policymakers as they 
will understand the quality of service and what should be improved if any.

Having synthesized and summarized the previous research, the study focuses on a particular eservice, the quality of online vehicle registration provided by the Ministry. The research questions of this study are how is the quality of the online vehicle registration in terms of (1) website design? (2) reliability? (3) citizen support? (4) trust? (5) accessibility? Additionally, (6) how do customers satisfy with the online vehicle registration? and (7) what encourages people to use online vehicle registration?

The research hypothesis for this research is: website design, reliability, citizen support, trust, and accessibility of the online system all have positive influences on overall service quality.

This research paper intends to describe the quality of service of vehicle plate online registration of MoPWT and to capture perspectives of online customers on service of vehicle plate online registration of MoPWT.

\section{Research Methods}

This research employs a mixed method methodology for two main reasons. First, numeric data tells the level of satisfaction people have with the online service while people's opinions from a qualitative method can add more value by supporting and explaining the results obtained from a quantitative method. Findings from the quantitative method could be generalized whereas the qualitative method offers a detailed description, enable those involved in the research to interact and allow more open to describe their feelings (Neuman, 2011; Yin, 2013). Therefore, using a mixed method can compensate for each method's flaws and shortages. Second, most of the previous studies did not employ a mixed method methodology. Thus, a mixed method can add more value and compare the data obtained from different methods. Additionally, research findings' quality and reliability can be improved significantly.

The research sampling technique is based on respondents' availability of both internet access and time to participate. The link to complete the online questionnaire was distributed through different channels, such as e-mails, telegram, and Facebook. Since the total population cannot be attained through the MoPWT's website, the research sample size is 100 online questionnaire respondents and ten in-depth interviewees. The author designs a questionnaire with 43 items. The responses are then recorded online. The interview protocol consists of eight main questions. With permission, the researcher uses a recorder and takes notes of what has been said by the interviewees. The questionnaire takes about 5 minutes to complete, while the interviews take about 30 minutes. Transcripts and analyses are produced and discussed to fit with each theme. The answer is converted to numeric data with code from 1 to 5 (1=strongly disagree and 5=strongly agree). The median score for each question is generated and grouped based on their themes.

The online questionnaire consists of a page describing the research's objectives and a question asking the participants for their consent to complete the questionnaire. The interviewees are informed that a recorder is on and notes are taken. The codes are produced instead of using words except for quotations from interviewees. After research has been 
written, all information is deleted for security and confidentiality purposes.

\section{Results and Discussion}

It can be seen from table 1 that among 100 respondents ( 7 of them did not indicate their gender), 55 are male, equal to $59.1 \%$. Those aged 30 to 34 represent most respondents with $43.8 \%$ and 25 to 29 years old with 39.3\%. About half of them are married. Interestingly, respondents are considered as well-educated since they have finished higher education or enrolled in university. Eighty-nine respondents are living in Phnom Penh and over 60 respondents are working in the public sector, while 25 are working in the private sector. Therefore, it can be concluded that the majority of respondents are aged between 25 to 34 and working in the public sector.

Table 1 Demographic data of online questionnaire respondents

\begin{tabular}{lll}
\hline Gender & Frequency & Percent \\
\hline Male & 55 & 59.1 \\
\hline Female & 38 & 40.9 \\
\hline Total & 93 & 100.0 \\
\hline Age group & Frequency & Percent \\
\hline $20-24$ & 6 & 6.7 \\
\hline $30-34$ & 35 & 39.3 \\
\hline $35-39$ & 39 & 43.8 \\
\hline $40-45$ & 8 & 9.1 \\
\hline Total & 1 & 1.1 \\
\hline Status & 89 & 100.0 \\
\hline Single & Frequency & Percent \\
\hline Married & 48 & 50.5 \\
\hline Total & 47 & 49.5 \\
\hline Types of occupation & Frequency & 100.0 \\
\hline Business people & 10 & Percent \\
\hline Private staff & 25 & 10.0 \\
\hline Public staff & 63 & 25.0 \\
\hline Others & 2 & 63.0 \\
\hline Total & 100 & 2.0 \\
\hline
\end{tabular}

Source: Online Questionnaires (2021)

The five main components of quality of online vehicle plate registration are website design, reliability, citizen support, trust, and accessibility.

\section{Website Design}

Figure 1 shows the median score of the 5-point Likert Scale on the website design components and its five areas of attractiveness, arrangement, form format, instruction for completion, and easiness. Respondents assess those areas from 0 to 5 scale (1= strongly disagree, $2=$ disagree, $3=$ normal, $4=$ agree, and $5=$ strongly agree). Figure 1 indicates that most respondents perceive it is normal for the website design concerning its attractiveness. However, it is rated as a low level for areas of arrangement or 
preparedness of the website (1). Additionally, the form format related to website design has a median score of 2, which means disagree. Precisely, customers disagree with the statement that the application form format is clear and acceptable.

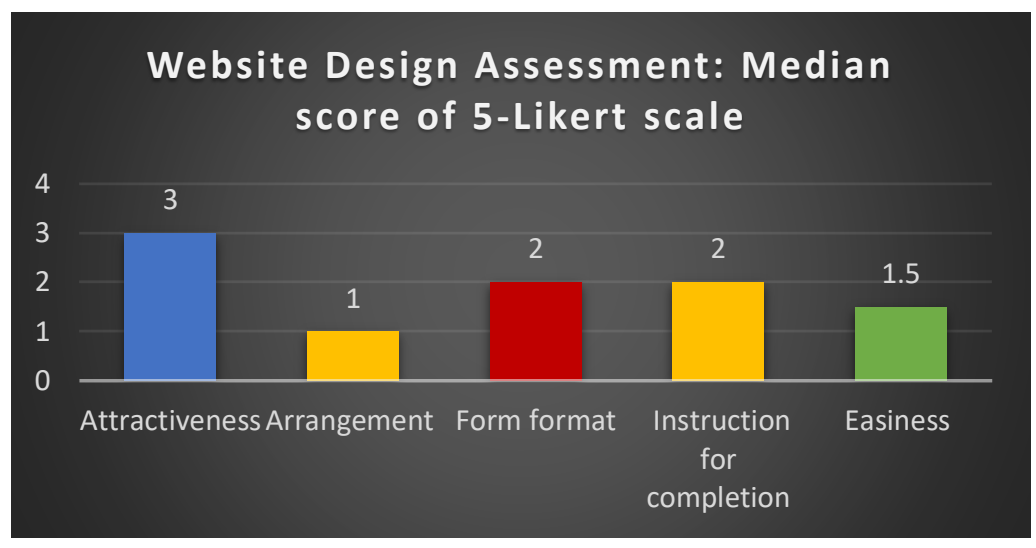

Figure 1 Website design assessment Source: Online Questionnaires (2021)

When asking about the website design's appearance, the interviewees seem to state that it is somehow acceptable as it can be read and not too much information, which can be too messy on the screen. Interviewees agree that they can quickly look for content and guidance on their computers when accessing the ministry website. However, an interviewee said that

"I think it is quite attractive to see the form available online, although it is a bit hard for me to see and understand at the first glance."

Another interviewee said:

"The design is simple, not too much advance. However, I like it because we need simple instructions, which can make it easy to follow."

On average, respondents disagree that the instruction and procedures in filling the form are explicit and quickness in completing the form (2). Finally, it is also very poor for easiness in operation until the end of payment (1). Participants did not mention any change they would like to see in website design despite quite low median scores. This can be implied that it does not have much influence on people's perception towards the quality of the service.

In this case, despite a low rate, people accepted it and did not urge any changes in website design. This result shows differences from previous research that claims an acceptable website design can determine the level of quality of services. Flavian et al. (2009) affirm that web design is a major factor in receiving positive results since it influences the users' insights and manners. Graham and Henman (2019) pinpoint the importance of website design that it does not only provide choices for users but also offers assumptions, organize and display the quality and ability of users, which results in people continuing to use the service. 


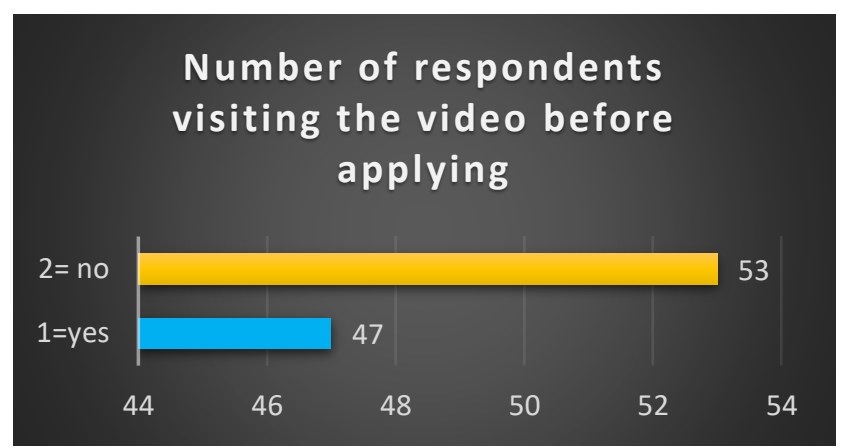

Figure 2 Number of respondents visiting the video before applying

Source: Online Questionnaires (2021)

There is a question asking people whether they have an experience of watching a video that intends to show the process, procedures, and the required documents for applying for plate registration in the Ministry's website. As shown in figure 2, fifty-three respondents say they have watched the video, while 47 say no. Those who have visited or viewed said:
"I think it is a waste of time to see the video, and I believe I can do it without viewing the video. So I just applied it directly."

"I did not see the video because I did not know that there was one. Maybe I did not see it, and I rushed to see the plates which are available online."

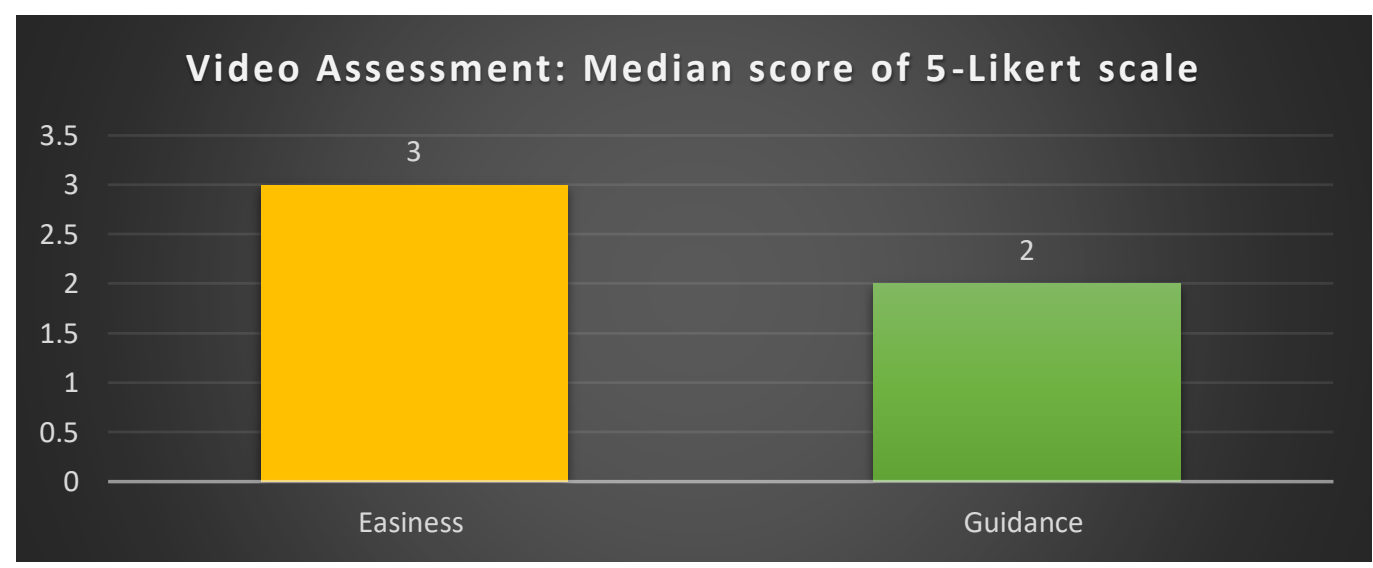

Figure 3 Video Assessment

Source: Online Questionnaires (2021)

Figure 3 shows respondents' perceptions towards two video areas, which intends to guide and support people in applying from the beginning to the end. These two areas are easy to complete due to the video guidance and detailed instructions for procedures and required documents. It indicates that the video does not provide easiness and detailed guidance since the score is 3 
(Neutral) and 2 (Disagree), respectively.

A few interviewees also mentioned the video that intends to guide people in applying until they get the vehicle plates. However, an interviewee stated that

"the process seems to be easy as shown in the video, but not in reality. In practice, filling out the form and submiting the scanned documents is not that easy. There are problems that we need to visit the officials that the video does not mention".

However, there is an interviewee who has a different view and raises that:

"the video allows the car owner to process documents faster because at least I know what I should prepare and the procedures I have to go through."
Previous researchers have not considered the videos, graphs, or pictures as one element to access the website design as this research does. This is due to real practice.

\section{Reliability}

Figure 4 concerning reliability shows that the score of security regarding offering e-mail addresses and phone numbers, on-time provision of service online is 2.5, which can mean either disagree or normal. However, it is unsatisfactory for an error-free transaction (1.5) and the website's security and safety (2=Disagree). Interestingly, four interviewees said that after attempting to apply online themselves unsuccessfully, they requested for services from intermediary or other agents to apply on their behalf. One of them reported that:

"I think it is too difficult for me to prepare the documents and apply with the bank account as I did it wrong once already."

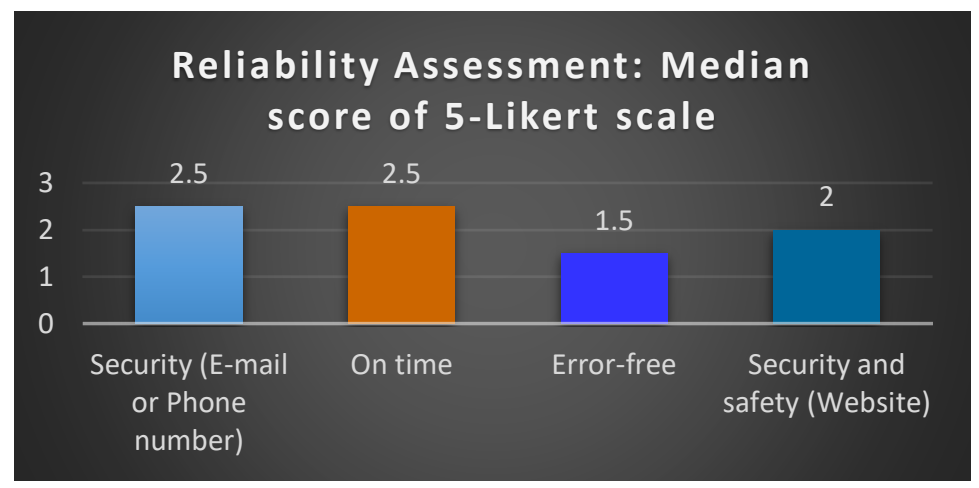

Figure 4 Reliability Assessment Source: Online Questionnaires (2021) said:

Similarly, another interviewee

"I completed the form and submitted the documents, and paid about 50 USD.
However, I had a problem with the document as they said. Then I asked for a refund. Nevertheless, the officials said they could not 
make a refund. It is unfair and upset me the most."

The reason for a low level of quality rate of reliability is because of people's experience. They did not receive the plates as expected, both delay in time and the refund could not be made after requesting. Respondents also commented that they preferred to pay with the bank for its safety and security purposes. The available plate numbers did not load correctly and immediately. The result strengthens the findings from previous research. Ding et al. (2014) emphasize the significance of reliability including software reliability and actual reliability for the user experience. Bartuskova et al. (2015) show that if the loading speed is on time and information is secured, websites' performance is considered to be high, and thus users are satisfied with the service. Similarly, Wang et al. (2018) stress that time series and systems that focus on service-oriented are well-perceived by users if they are taken into account considerably. However, the research shows the underlying problems of reliability and the actual conduct of users after experiencing problems using online services.
Figure 5 shows the median score of four areas of citizen support; enough support as requested, the officials' immediate response, helpfulness, and the officials' capability and knowledge. Enough support and helpfulness share the same score, which is 2 (means respondents disagree). The score for the areas of immediate responsiveness and capability and knowledge of the officials is the same, 2.5 (disagree or normal). Interviewees commented that the officials did not perform their tasks and provide public service to customers fairly and politely. They may ask for further fees to help arrange their documents properly and have their plates equipped faster. One interviewee reported that: "My wife ID is made in the province and the authority said it is impossible to have a Phnom Penh vehicle plate. They required a residential certificate to prove that we are living in Phnom Penh. I then tried to prove that she is working in Phnom Penh. Finally, the problem is solved. But it took a long time, and I had to visit many times"

\section{Citizen support}

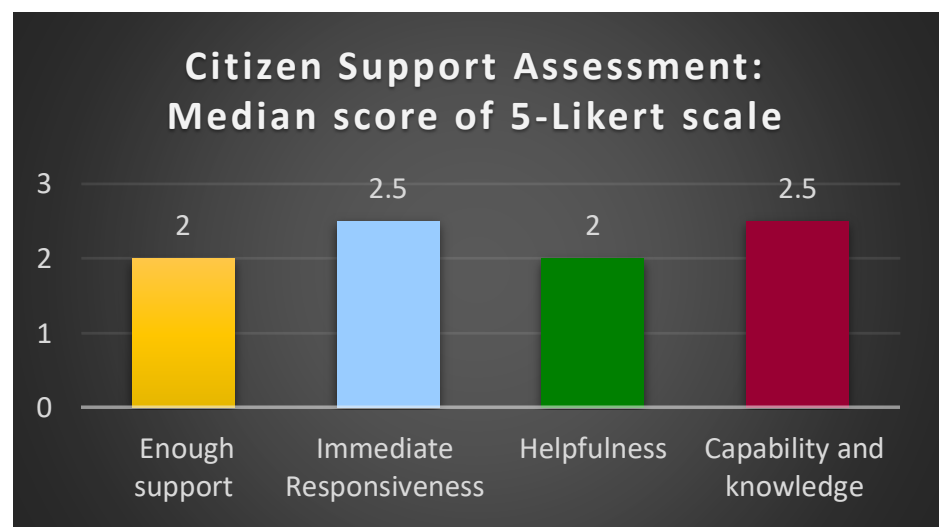

Figure 5 Citizen Support Assessment

Source: Online Questionnaires (2021) 
Another interviewee
expressed that:
"One officier directed me to
other officials by pointing
toward another man to help
arrange the documnts and
you might need to give them
some money for coffee."
Unhelpful staff during the time of having their plates equipped and inadequate support when problems arise are the two main reasons for the low median score for quality of service. Nielsen (2017) compares approaches of Danish and Japanese in e-Governance and finds that enough support and in search of consensus is fundamental to improve the service delivery. Similarly, Carter et al. (2016) conclude that ease of use with adequate support has a positive impact on intention to use. This is also the case in Cambodia, people perceive citizen support as an important part of service quality and this reflects in the low quality of online service when rated for overall quality. In this section, it is interesting to note that people still have to visit officials and corruption can occur.

\section{Trust}

Figure 6 indicates the score of three areas of trust. They are an ontime service for equipping vehicle plates, correct transactions, and trust or confidence with online payment. Interestingly, all three areas' score is the same, which is 2.5 (disagree or normal). This can be seen from their response to further questions that some respondents pay for the transaction. However, they did not receive the service, and the officials could not refund them. That is also similar to the above about reliability. People have paid for the service; however, they could not receive the plates as they expected. Other respondents said they trust the system since the government agency operates it, and thus they trust the payment method.

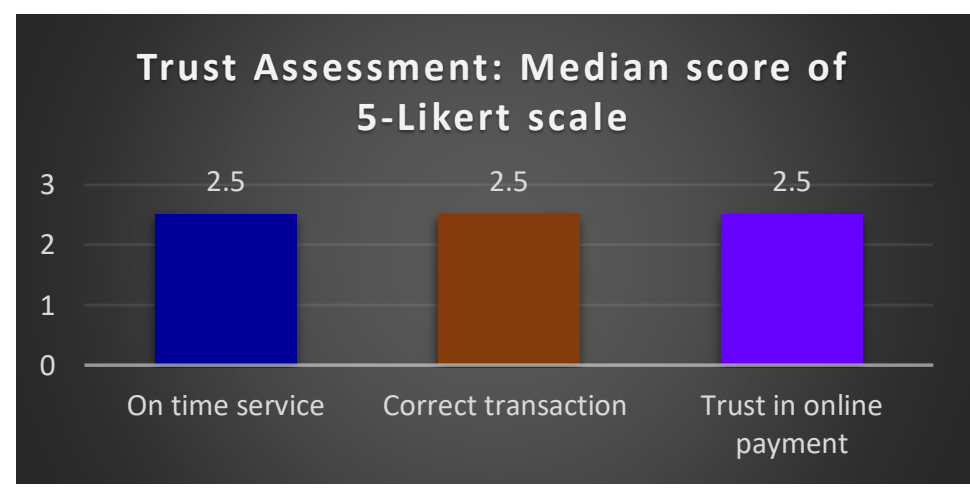

Figure 6 Trust Assessment

Source: Online Questionnaires (2021)

People perceive that the online service is neither trusted nor untrusted. However, people trust the payment online since it is with the bank cooperating with the government. Carter et al. (2016) claim that the nature of trust has a positive relation to internet trust and government trust. This means that if people trust the internet and the 
government, they are likely to use the service online. In this case, it shows similar trends that people trust online payment. Consequently, they choose to pay online. However, this might be because of the only option they have when using online services. Chu et al. (2012) find the significance of customer satisfaction and trust on the service quality. Similarly, Torresmoraga et al. (2013) assert that there is a direct influence of service quality on satisfaction; however, an indirect on trust. We can consider that trust is an important element contributing to the overall quality of service.

\section{Accessibility Assessment}

Regarding accessibility, four areas of accessibility are accessing the website, fees, no discrimination or fair treatment, and easiness in following up the process. It can be seen from figure 7 that the score for accessing the website and fair treatment for all (no discrimination against anyone) is 1.5, which is low. However, for fees and easiness in following up, the score is 2.5. One of the interviewees said:

"The service is acceptable if compared with the old process; which was time consuming, complicated, and expensive. For this one, I chose a normal plate which is available online, so I spend only about 30 USD, which is a reasonable price."

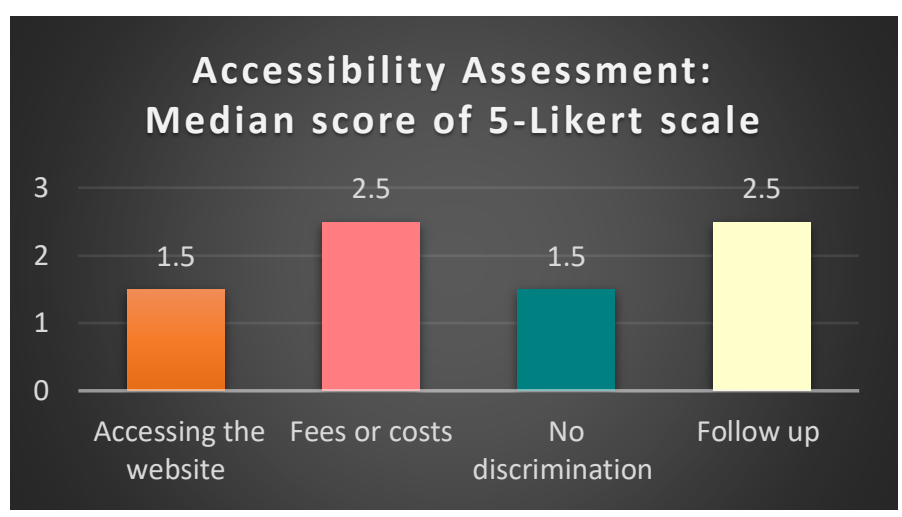

Figure 7 Accessibility Assessment Source: Online Questionnaires (2021)

Some interviewees also raised the cost as acceptable if car owners choose the available plate online but not to request or to bid. An interviewee expressed that:

"I spent more than 3 million riles on the plate I preferred, which was very expensive. However, I had no other options. The ministry was the one who set the price"

Another interviewee said:
"After two days, we can have our car license and plate equipped on our cars. However, the cost is significantly more expensive than applying on my own. For a short plate, it costs about 85 USD, and for the long plate, it is 165 USD. The cost is just for the normal plate without having the chance to choose or bid." 
From the comments, the price is reasonable and fair as it is available online, and the price is there. However, it is unfair since they have to pay more extra fees for preferred plates. In the end, they also pay an additional charge for officials at the time of equipping and receiving licenses. In other research, concerning accessibility, there are complex results. While Bhatnagar (2007) examined the direct economic effects in reducing operating costs, tax revenue collection, and the transaction fee in India and Chile. A direct causal relationship could not be confirmed because of the difficulty in differentiating economic benefits resulting from computerization and other factors. Conversely, von Haldenwang (2004) found that there was a $20 \%$ cost savings annually for the e-procurement system in Brazil. In this case, the transaction fee varies, and cannot be determined whether eservice help save people and the government's money.

Quality in general or level of satisfaction

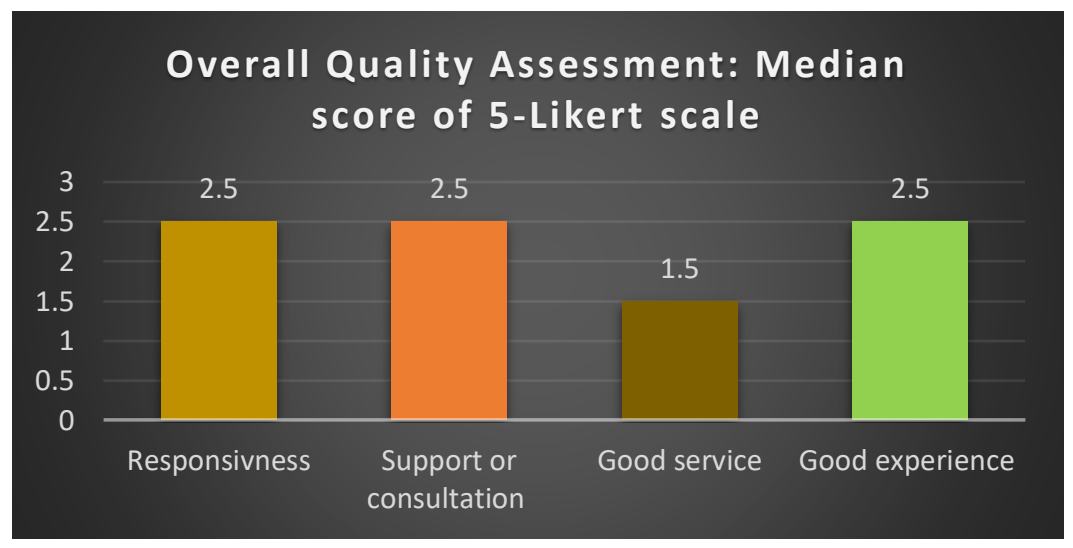

Figure 8 Overall Quality Assessment Source: Online Questionnaires (2021)

Figure 8 indicates the score of overall quality assessment, including responsiveness, supporting service, overall view on service, and experience. The score for responsiveness, support, and experience is 2.5 , while the overall view on service is 1.5 . The comments are that the service is convenient, fast, and acceptable. Concerning the overall quality of this online service, interviewees tend to differentiate between the online and face-to-face meetings with the officials at the place of receiving plates. The common reasons for using this online vehicle plate registration service are convenience and saving time. customers saved time since they do not have to visit the officials frequently, and traveling is unnecessary, but only when they have problems with their transactions and when they get their plates.

There are some issues with using this online service. Regarding support, customers would prefer to see and receive the service from more reliable, responsible, and friendly officials rather than those who are arrogant and asking money indirectly by acting ignorant to the customers. A few interviewees stated that they were upset with the online service, for they do not receive their plates when they apply independently and could not receive a refund when they could not have their vehicle registered. Vatolkina et al. (2020) 
conclude that customer experience has a strong effect on their satisfaction and their intention to repurchase products. Al-nasser et al. (2013) concluded that service quality is of critical importance in affecting customer trust in online service, resulting in a direct positive influence of perception on service quality on user trust. Sharma (2018) suggested that both qualities of information and the online service itself are the prime factors affecting customer satisfaction and the sustainability of service. Noorshella et al. (2015) detecting key factors of e-service quality of business in Malaysia. The study finds that the key elements of e-service quality are the quality of information of products, the design of a web, the nature of security and privacy of information, and customers' expectation of service. This research also strengthens the results of previous research in that when these issues occur concerning their experience in online service, it affects their perception of the overall quality of the service. The average score of dimensions of quality in the research is 2, which is the same score for the overall quality. This implies that most of the elements as stated in the hypothesis of this research are correct. Those dimensions affect people's perception of service quality.

It can be assumed that customers usually spend around two to three weeks to complete the whole transaction and have the plated equipped on their car. However, if people do not want to apply on their own or do not have their account, they ask the intermediary to process on their behalf. This is also the case in Bhutan, where people go for an intermediary (Miyata, 2011). This also happens when people would like it to be faster. The service is thus subject to be improved to cater to the customers' needs.
In conclusion, this section shows that this online service's quality is not well-accepted by the majority of the customers. There are problems that the Ministry should take into account to deliver better service, particularly on citizen support and reliability. Reducing any forms of corruption is also necessary.

\section{Conclusion}

The research objectives are reached since the quality of the online service and level of citizen satisfaction are shown. The quality is considered as not well-accepted or not at a satisfying level since customers who have experienced the online service before rate quite low for most of the elements of quality; website design, reliability, citizen support, trust, and accessibility. The score is 2, meaning people disagree that service quality is good or acceptable. The underlying issues that might affect the quality, range from corruption and unhelpful officials to denial of getting a refund. Reliability and citizen support elements should be improved to build trust in the system and the whole quality of service. The overall quality also defines the customer's level of satisfaction. Therefore, in this research, customers feel either normal or not satisfied with the service by revealing some issues they encountered.

There are at least two points to be considered. First, there are hidden issues in the service. While in general, people expect that an online service can improve service delivery and reduce corruption, time, and costs, these issues still occur due to the designation of the whole system and the country's context. People's knowledge and the level of their trust in the officials to deliver the service is still low that people choose not to apply on their own. Second, 
corruption still exists when there are chances of face-to-face meetings between the customers and officials. These issues should be taken into account, and policymakers should find solutions to such issues.

There are a few limitations of the study concerning the number of participants and the possibility of losing meaning because of translation. There are possibilities of doing similar research or the same topic to this study by changing the methodology and having a different conceptual framework. Since this research consists of a few limitations as mentioned above, future researchers could improve the reliability of the research by including more participants. Also, they can study the same topic about the quality with different components to see whether there are different results compared to this research or choose other online services provided by the government. Alternatively, they can compare the public online service with the private sector service.

\section{Acknowledgments}

I would like to express my gratitude to Mr. Saing Hay, Professor of Public Administration and Management, for his excellent supervision of this research. I would like to extend my grateful appreciation to University of Cambodia and those who have been involved in this research.

\section{References}

Abu-Shanab, E. A. (2015). Reengineering the open government concept: An empirical support for a proposed model. Government Information Quarterly, 32(4), 453-463. https://doi.org/10.1016/j.giq.20 15.07.002

Al-nasser, M., Yusoff, R. Z., \& Islam, R.
(2013). E-Service Quality and its Effect on Consumers , Perceptions Trust. American Journal of Economics and Business Administration, 5(2), 47-55. https://doi.org/10.3844/ajebasp .2013 .47 .55

Alanezi, M., Kamil, A., \& Basri, S. (2010). A proposed instrument dimensions for measuring egovernment service quality. International Journal of $U$-and $e$ Service, 3(4), 1-18.

Bartuskova, A., Krejcar, O., \& Soukal, I. (2015). Framework of design requirements for E-learning applied on blackboard learning system. In Lecture Notes in Computer Science (including subseries Lecture Notes in Artificial Intelligence and Lecture Notes in Bioinformatics). https://doi.org/10.1007/978-3319-24306-1_46

Bertot, J. C., Jaeger, P. T., \& Grimes, J. M. (2012). Promoting transparency and accountability through ICTs, social media, and collaborative e-government. Transforming Government: People, Process and Policy, 6(1), 78-91.

https://doi.org/10.1108/17506 161211214831

Bhatnagar, S. (2007). Impact assessment study of computerized services delivery projects from India and Chile (No. 2). Washington, D.C.

Blut, M., Chowdhry, N., Mittal, V., \& Brock, C. (2015). E-Service Quality: A Meta-Analytic Review. Journal of Retailing, 91(4), 679700.

https://doi.org/10.1016/j.jretai. 2015.05.004

Carter, L., Weerakkody, V., Phillips, B., \& Dwivedi, Y. K. (2016). Citizen Adoption of E-Government Services: Exploring Citizen 
Perceptions of Online Services in the United States and United Kingdom. Information Systems Management, 33(2), 124-140. https://doi.org/10.1080/10580 530.2016.1155948

Chu, P., Lee, G., \& Chao, Y. (2012). Service Quality , Customer Satisfaction, Customer Trust, and Loyalty in an E- Banking Context. Social Behavior and Personality An International Journal, 40(8), 1271-1284. https://doi.org/10.2224/sbp.20 12.40.8.1271

Ding, Z., Chen, M. H., \& Li, X. (2014). Online reliability computing of composite services based on program invariants. Information Sciences, $\quad 264, \quad 340-348$. https://doi.org/10.1016/j.ins.20 13.05.020

Flavian, C., Gurrea, R., \& Orus, C. (2009). Web design: A key factor for the website success. Journal of Systems and Information Technology, 11(2), 168-184. https://doi.org/10.1108/13287 260910955129

Graham, T., \& Henman, P. (2019). Affording choice: how website designs create and constrain 'choice'. Information Communication and Society, 22(13), 2007-2023. https://doi.org/10.1080/13691 18X.2018.1476570

IGI. (2020). What is E-Services. Retrieved 21 March 2021, from IGI Global website: https://www.igiglobal.com/dictionary/communi ty-broadband-networks-and-theopportunity-for-e-governmentservices/8918

Milakovich, M. E. (2012). Digital governance: new technologies for improving public service and participation. New York/London: Routledge.

Mistry, J. J., \& Jalal, A. (2012). An empirical analysis of the relationship between egovernment and corruption. International Journal of Digital Accounting Research, 12, 145176.

https://doi.org/10.4192/15778517-v12_6

Miyata, M. (2011). Measuring impacts of e-government support in least developed countries: a case study of the vehicle registration service in Bhutan. Information Technology for Development, 17(2), 133-152. https://doi.org/10.1080/02681 102.2010.537251

Neuman, W. L. (William L. (2011). Social research methods: qualitative and quantitative approaches. Boston: Allyn \& Bacon.

NiDA \& JICA. (2009). The Follow-up Study Report on e-Government Service Deployment Plan for Royal Government of Cambodia October 2009. Retrieved from https://www.jica.go.jp/project/c ambodia/0609376/04/pdf/05_e gov_2009_e.pdf

Nielsen, M. M. (2017). eGovernance frameworks for successful citizen use of online services: A Danish-Japanese comparative analysis. JeDEM - EJournal of EDemocracy and Open Government, 9(2), 68-109. https://doi.org/10.29379/jedem .v9i2.462

Noorshella, C. N., Abdullah, A. M., \& Nursalihah, A. R. (2015). Examining the Key Factors Affecting e-Service Quality of Small Online Apparel Businesses in Malaysia. Sage Open, 5(2), 110.

https://doi.org/10.1177/21582 44015576550

Papadomichelaki, X., \& Mentzas, G. (2012). E-GovQual: A multipleitem scale for assessing e- 
government service quality. Government Information Quarterly, 29(1), 98-109. https://doi.org/10.1016/j.giq.20 11.08.011

Sang, S., Lee, J. D., \& Lee, J. (2009). Egovernment adoption in ASEAN: The case of Cambodia. Internet Research, 19(5), 517-534. https://doi.org/10.1108/10662 240910998869

Sharma, G., \& Lijuan, W. (2015). The effects of online service quality of e-commerce Websites on user satisfaction. The Electronic Library, 33(3), 468-485. https://doi.org/10.1108/EL-102013-0193

Taherdoost, H. (2018). Development of an adoption model to assess user acceptance of e-service technology: E-Service Technology Acceptance Model Development of an adoption model to assess user acceptance of e-service. Behaviour \& Information Technology, 37(2), 173-197.

https://doi.org/10.1080/01449 29X.2018.1427793

Tan, C.-W., Benbasat, I., \& Cenfetelli, R. T. (2013). IT-Mediated Customer Service Content and Delivery in Electronic Governments: An Empirical Investigation of the Antecedents of Service Quality. MIS Quarterly, 37(1), 77-109.

Torres-moraga, E., Vásquez-parraga, A. Z., \& Farías, A. (2013). The Effects of Service Quality on
Customer Trust and Satisfaction in Internet Banking. Estudios de Administración, 20(1), 1-36.

Vatolkina, N., Gorbashko, E., Kamynina, N., \& Fedotkina, 0 . (2020). E-Service Quality from Attributes to Outcomes: The Similarity and Di ff erence between Digital and Hybrid Services. Journal of Open Innovation: Technology, Market, and Complexity Article, 6, 1-21.

von Haldenwang, C. (2004). Electronic government (Egovernment) and development. European Journal of Development Research, 16(2), 417-432. https://doi.org/10.1080/09578 81042000220886

Wang, H., Wang, L., Yu, Q., Zheng, Z., \& Yang, Z. (2018). A proactive approach based on online reliability prediction for adaptation of service-oriented systems. Journal of Parallel and Distributed Computing, 114, 7084.

https://doi.org/10.1016/j.jpdc.2 017.12.006

Wirtz, B. W., \& Birkmeyer, S. (2015). Open Government: Origin, Development, and Conceptual Perspectives. International Journal of Public Administration, 38(5), 381-396. https://doi.org/10.1080/01900 692.2014.942735

Yin, R. K. (2013). Case Study Research: Design and Methods. USA: SAGE Publications.

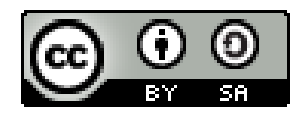

(C) 2021 by the Author. Submitted for possible open access publication under the terms and conditions of the Creative Commons Attribution- ShareAlike (CC BY SA) license (https://creativecommons.org/licenses/by-sa/4.0/). 